\title{
Diversity and Transmission of Gut Bacteria in Atta and Acromyrmex Leaf-Cutting Ants during Development
}

\author{
Mariya Zhukova*, Panagiotis Sapountzis, Morten Schiøtt and Jacobus J. Boomsma* \\ Centre for Social Evolution, Department of Biology, University of Copenhagen, Copenhagen, Denmark
}

The social Hymenoptera have distinct larval and adult stages separated by metamorphosis, which implies striking remodeling of external and internal body structures during the pupal stage. This imposes challenges to gut symbionts as existing cultures are lost and may or may not need to be replaced. To elucidate the extent to which metamorphosis interrupts associations between bacteria and hosts, we analyzed changes in gut microbiota during development and traced the transmission routes of

OPEN ACCESS

Edited by:

David Berry,

University of Vienna, Austria

Reviewed by:

Frank O'Neill Aylward, Virginia Tech, United States

Benoit Chassaing,

Georgia State University,

United States

${ }^{*}$ Correspondence:

Mariya Zhukova

mariya.zhukova@bio.ku.dk

Jacobus J. Boomsma

jjboomsma@bio.ku.dk

Specialty section:

This article was submitted to

Microbial Symbioses,

a section of the journal

Frontiers in Microbiology

Received: 13 June 2017 Accepted: 21 September 2017

Published: 10 October 2017

Citation:

Zhukova M, Sapountzis P, Schiøtt M and Boomsma JJ (2017) Diversity and Transmission of Gut Bacteria in Atta and Acromyrmex Leaf-Cutting

Ants during Development.

Front. Microbiol. 8:1942.

doi: 10.3389/fmicb.2017.01942 dominant symbionts from the egg to adult stage in the leaf-cutting ants Acromyrmex echinatior and Atta cephalotes, which are both important functional herbivores in the New World tropics. Bacterial density remained similar across the developmental stages of Acromyrmex, but Atta brood had very low bacterial prevalences suggesting that bacterial gut symbionts are not actively maintained. We found that Wolbachia was the absolute dominant bacterial species across developmental stages in Acromyrmex and we confirmed that Atta lacks Wolbachia also in the immature stages, and had mostly Mollicutes bacteria in the adult worker guts. Wolbachia in Acromyrmex appeared to be transovarially transmitted similar to transmission in solitary insects. In contrast, Mollicutes were socially transmitted from old workers to newly emerged callows. We found that larval and pupal guts of both ant species contained Pseudomonas and Enterobacter bacteria that are also found in fungus gardens, but hardly or not in adult workers, suggesting they are beneficial only for larval growth and development. Our results reveal that transmission pathways for bacterial symbionts may be very different both between developmental stages and between sister genera and that identifying the mechanisms of bacterial acquisition and loss will be important to clarify their putative mutualistic functions.

Keywords: symbiosis, gut microbiota, bacterial transmission, Mollicutes, Wolbachia, 16S rRNA sequencing

\section{INTRODUCTION}

Bacterial symbionts of insects can either be vertically transmitted or acquired de novo from the environment in every generation. Obligate symbionts are strictly vertically transmitted, but facultative symbionts can be both vertically and horizontally transmitted (Moran et al., 2008; Fisher et al., 2017) and transmission mode appears unrelated to symbiont bacteria having extracellular 
or intracellular lifestyles (Salem et al., 2015). In solitary insects vertical transmission of symbiotic bacteria can occur via different routes, including the egg's cytoplasm, the sperm, or substances covering the eggs (Bright and Bulgheresi, 2010; Kaiwa et al., 2014; Watanabe et al., 2014). Complexity culminates in ants and other social insects where vertical transmission can also be achieved through behavioral interaction mechanisms such as larval feeding or grooming (Schmid-Hempel, 1998). This form of vertical transmission at the colony level, based on horizontal transmission between colony members, is unique for social insects (Boomsma et al., 2005) and may facilitate the coexistence and possible co-adaptation of symbiont bacteria and their hosts (Kwong and Moran, 2016). However, different symbionts might be functionally important at different developmental stages of insects, depending on their diet and lifestyle. The question arises, therefore, whether any symbiotic bacteria of ants and other social insects are acquired by direct vertical transmission, and to what extent indirect vertical transmission via nestmates involves the larval stage or not. For symbionts where it does, it might require the evolution of special mechanisms to transmit bacteria during the intricate process of metamorphosis, when extensive cell death occurs in most tissues, including the gut, before a completely restructured adult emerges (Gilbert et al., 2005; Wu et al., 2006; Parthasarathy and Palli, 2008).

Among the social insects, the diversity and transmission of gut bacterial symbionts across developmental stages has been studied in honeybees, termites, and several ant species. It has become clear that larvae of the honeybee Apis mellifera have very few or no bacteria in their gut, so that adults need to acquire their gut microbiome through interactions with older nestmates or hive material after emergence (Gilliam, 1971; Gilliam and Prest, 1987; Martinson et al., 2012). The diversity of bacteria in the guts of adult honeybees remains low, as expected for insects with specialized diets (Martinson et al., 2011; Yun et al., 2014), and most of the dominant bacterial species have now been shown to be specialized mutualists with roles in diet supplementation or disease defense (Engel et al., 2012; Kwong and Moran, 2016). In contrast, larvae of the omnivorous fire ant Solenopsis invicta digest solid food, turning it into a liquid that workers and queens can ingest, which likely explains that the diversity of larval gut bacteria depends on the geographical location and the food consumed by the colony (Lee et al., 2008; Lee and Hooper-Bui, 2012). A prominent example of direct vertical transmission occurs in Camponotus carpenter ants, where transovarially transmitted Blochmannia endosymbionts persist in specialized cells that are intercalated in the midgut tissue of all developmental stages (Sauer et al., 2002; Stoll et al., 2010). Wolbachia bacteria are endosymbionts present in the guts and other tissues of many insects (Pietri et al., 2016). They are widespread among ant species (Wenseleers et al., 1998) and maternally transmitted by default, as horizontal transfer appears to be exceedingly rare and operates at evolutionary rather than ecological time scales (Shoemaker et al., 2000; Viljakainen et al., 2008; Frost et al., 2010; Martins et al., 2012).

Leaf-cutting ants of the genera Atta and Acromyrmex have even more specialized diets than honeybees, because they specialize on cultivating a basidiomycete fungal symbiont that provides the only source of nutrition for the larvae. Adult workers also ingest plant sap while cutting leaves and they ingest juice from fallen fruits (Quinlan and Cherrett, 1979), but this does not appear to have increased the diversity of their gut microbiomes. Recent studies have shown that the diversity of the gut bacterial community of adult workers of Acromyrmex echinatior is as low as in honeybee workers and mainly composed of a handful of Wolbachia, Mollicutes, and Rhizobiales bacteria, whereas gut microbiome diversity in Atta cephalotes workers, including Mollicutes, and Rhizobiales, is only slightly higher (Sapountzis et al., 2015; Sapountzis et al., in revision). The Wolbachia of Acromyrmex are found widespread in the worker bodies and are very unlikely to be reproductive parasites (Andersen et al., 2012). The Rhizobiales form biofilms in the adult worker hindgut and appear to have nitrogen acquisition or preservation functions (Sapountzis et al., 2015), whereas the putative function of the Mollicutes remains to be clarified. There is no indication that Mollicutes bacteria living in Acromyrmex and Atta leaf-cutting ants are pathogens because they are abundantly present in healthy ant workers.

In other insects, the presence of symbiotic bacteria in specific developmental stages has been used to narrow down the highly diverse potential spectrum of putative functions, which include supplementation of essential nutrients, defense against pathogens, and detoxification of poisonous compounds (Engel and Moran, 2013; Vigneron et al., 2014; Ben-Yosef et al., 2015). In the present study we analyze the abundance and composition of the bacterial community in larval, pupal, and adult guts of two Panamanian leaf-cutting ants, monitor mechanisms of acquisition and changes in bacterial abundance across developmental stages, and discuss possible impacts of the presence or absence of gut bacteria on the health of the ant hosts.

\section{MATERIALS AND METHODS}

\section{Ant Collection and Maintenance}

Ant colonies were collected in Gamboa, Republic of Panama, in 2014. We used four Acromyrmex echinatior colonies (Ae711, Ae712, Ae715, and Ae717) and three Atta cephalotes colonies (AcW, AcCr, and AcCa) for sampling workers and brood immediately after collection in the field. Specimens belonged to three developmental stages: actively feeding larvae with clearly visible (under a stereoscope) guts, mature (brown) pupae close to hatching, and adult workers taken either from the top of the fungus garden or foraging around it. For Acromyrmex, we collected large workers and for Atta media workers of comparable size, of which individual guts were dissected in Gamboa and washed in sterile phosphate-buffered saline (PBS, $\mathrm{pH} 7.4$ ), transferred to $2 \mathrm{ml}$ screw cap tubes, and stored at $-80^{\circ} \mathrm{C}$ until DNA extraction. For subsequent experiments in the lab to confirm bacterial transmission patterns, we sampled similar specimens from three other A. echinatior (Ae322, Ae360, and Ae507) and four other A. cephalotes (Ac2012-2, Ac2012-3, Ac2012-4, and Ac19BB) colonies maintained in rearing rooms in Copenhagen (since 1996-2012) at ca. $25^{\circ} \mathrm{C}$ and $70 \%$ relative humidity and fed with bramble leaves, fruit fragments and dry 
rice. Before dissections, individuals of all developmental stages (including eggs) were always surface-sterilized by submerging them into $70 \%$ ethanol and then $2.5 \%$ bleach.

To monitor transmission of gut bacteria in real time, we used three of the A. echinatior colonies (Ae322, Ae360, and Ae507) and two of the A. cephalotes colonies (Ac2012-2 and Ac2012-3) to isolate brood and workers. The infection status of workers was repeatedly confirmed with PCR [presence of known Mollicutes Operational Taxonomic Units (OTUs) EntAcro1 or EntAcro2, see Results; Sapountzis et al., 2015] before the start of the experiment and the following combinations of brood and workers were setup to monitor different transmission patterns: Ae360 pupae + Ae360 workers (transmission toward brood within a single colony where workers were infected with EntAcro1), Ae507 pupae + Ae322 workers [transmission across colonies with different Mollicutes infection; EntAcro1 and weak EntAcro2 (pupae) versus EntAcro2 and weak EntAcro1(workers)], Ac2012-2 pupae + Ac2012-3 workers and Ac2012-3 pupae + Ac2012-2 workers (transmission across colonies with similar double Mollicutes infection; EntAcro1 and weak EntAcro2). Mature pupae were isolated from colonies and put in large Petri dishes together with fungus garden material and workers from paired colonies. Petri dishes were checked daily for the presence of newly hatched ants and such callows were marked with paint dots on their gasters. After eclosion, callows were together for 1 day with workers from the paired colony to improve the survival of hatched callow workers, which mostly died when they were kept in isolation. Then callows were transferred to a second Petri dish either alone or accompanied by three major and three minor workers from the other colony for 21 days. Ants of both groups were fed with aqueous $10 \%$ sucrose solution throughout the experiment and five guts per colony were dissected for pupae and callows both on the first and on the 21st day.

\section{DNA Extraction and Illumina Miseq Sequencing}

DNA was extracted from frozen gut samples of field and lab colonies using the DNeasy blood and tissue kit (Qiagen) according to the manufacturer's instructions, with an extra step at which glass beads of $0.5 \mathrm{~mm}$ were added to lysis buffer and vortexed for $30 \mathrm{~s}$. All samples were eluted using $100 \mu \mathrm{l}$ of AE elution buffer, after which the extracted DNA from field colonies was sent to the Microbial Systems Laboratory at the University of Michigan for library preparation and 16S Miseq Illumina sequencing as described in Kozich et al. (2013). Sequences of the V4 region of the $16 \mathrm{~S}$ rRNA genes were amplified using 515F and 806R primers. Amplification was performed using AccuPrime Taq DNA polymerase with high fidelity using the following protocol: 1 cycle at $95^{\circ} \mathrm{C}$ for $2 \mathrm{~min}, 30$ cycles at $95^{\circ} \mathrm{C}$ for $20 \mathrm{~s}, 55^{\circ} \mathrm{C}$ for $15 \mathrm{~s}$ and $72^{\circ} \mathrm{C}$ for $5 \mathrm{~min}$, and then 1 cycle at $72^{\circ} \mathrm{C}$ for $10 \mathrm{~min}$. When this standard procedure did not provide enough PCR product for sequencing (larvae, pupae, and some workers of $A$. cephalotes), touchdown PCR was performed under the following conditions: 1 cycle at $95^{\circ} \mathrm{C}$ for $2 \mathrm{~min}, 20$ cycles at $95^{\circ} \mathrm{C}$ for $20 \mathrm{~s}$, the annealing temperature ranging from $60^{\circ} \mathrm{C}$ to $55^{\circ} \mathrm{C}$ (decreasing $0.3^{\circ} \mathrm{C}$ every cycle) for $15 \mathrm{~s}$ and $72^{\circ} \mathrm{C}$ for $5 \mathrm{~min}$, then 20 cycles with the same conditions but at a constant $55^{\circ} \mathrm{C}$ annealing temperature, and finally 1 cycle at $72^{\circ} \mathrm{C}$ for $10 \mathrm{~min}$. Data were deposited in GenBank (Bioproject PRJNA383138).

\section{PCR and Droplet Digital PCR (ddPCR)}

To check if Mollicutes are present in different developmental stages of ants from lab colonies, we used 16S rRNA genespecific primers for EntAcro1 and EntAcro2 (Supplementary Table S1). To detect Wolbachia, we used the wsp-specific primers (Braig et al., 1998) and the following PCR conditions: denaturation for $3 \mathrm{~min}$ at $94^{\circ} \mathrm{C}$, followed by 35 cycles of $30 \mathrm{~s}$ at $94^{\circ} \mathrm{C}, 30 \mathrm{~s}$ at the relevant annealing temperature (see Supplementary Table S1) and $30 \mathrm{~s}$ at $72^{\circ} \mathrm{C}$, and a 7 -min final extension at $72^{\circ} \mathrm{C}$.

For bacterial $16 \mathrm{~S}$ rRNA gene quantification we used the same DNA samples of guts from field colonies as for Illumina sequencing and a well-established protocol (Sze et al., 2014, see primers in Supplementary Table S1). The bacterial 16S rRNA gene copy load was normalized to the number of ants' gut cells in the sample using primers for the single-copy gene tbp (TATA-box-binding protein, Nygaard et al., 2016, Supplementary Table S1). The amplification process was performed in a BioRad's S1000 thermal cycler with the following protocol: 1 cycle at $95^{\circ} \mathrm{C}$ for $5 \mathrm{~min}, 40$ cycles at $95^{\circ} \mathrm{C}$ for $15 \mathrm{~s}$ and $60^{\circ} \mathrm{C}$ for $1 \mathrm{~min}$, 1 cycle at $4^{\circ} \mathrm{C}$ for $5 \mathrm{~min}$, and 1 cycle at $90^{\circ} \mathrm{C}$ for $5 \mathrm{~min}$, all at a ramp rate (heating change rate) of $2^{\circ} \mathrm{C} / \mathrm{s}$. Two types of negative controls were used for both experiments: water and non-template DNA extracted from a fungus garden of A. echinatior, which was reared for three passages on PDYA medium with $15 \mathrm{mg} / \mathrm{l}$ of tetracycline and $12 \mathrm{mg} / \mathrm{l}$ of streptomycin (Kooij et al., 2015). The negative control 16S bacterial load values never exceeded the range of values described previously for negative controls (Sze et al., 2014) and were below the range of values of our DNA samples. Fluorescence thresholds were chosen manually based on negative control experiments (Supplementary Table S1). The 16S rRNA gene copy number per host cell was calculated as the ratio of $16 \mathrm{~S}$ rRNA copies per half of the tbp copy number, taking into account that there are two gene copies of $t b p$ per diploid host cell. Similar procedures were performed to quantify Mollicutes density in transmission experiments with 16S rRNA gene-specific primers for EntAcro1 and EntAcro2 (Sapountzis et al., 2015, Supplementary Table S1), except that two additional steps were added for PCR: 1 cycle at $95^{\circ} \mathrm{C}$ for $5 \mathrm{~min}, 40$ cycles at $95^{\circ} \mathrm{C}$ for $15 \mathrm{~s}, 40 \mathrm{~s}$ at the annealing temperature (Supplementary Table S1) and $40 \mathrm{~s}$ at $72^{\circ} \mathrm{C}, 1 \mathrm{cycle}$ at $4^{\circ} \mathrm{C}$ for $5 \mathrm{~min}$, and $1 \mathrm{cycle}$ at $90^{\circ} \mathrm{C}$ for $5 \mathrm{~min}$, all at ramp rate of $2^{\circ} \mathrm{C} / \mathrm{s}$.

\section{Data Analyses}

To compare bacterial 16S rRNA gene copy densities across different samples, we used non-parametric tests in PAST3 because data were not normally distributed (Hammer et al., 2001). $P$-values below 0.05 were considered statistically significant. 16S rRNA gene sequencing data were analyzed using mothur (version 1.36.1, Schloss et al., 2009) and sequences were processed and filtered as described in the standard operating procedure (SOP) (Kozich et al., 2013). Two sets of reads for each sample were combined into contigs using default parameters in 
mothur, which allowed most sequencing errors to be removed. All sequences with ambiguous bases and lengths above $275 \mathrm{bp}$ were removed. We subsequently aligned filtered sequences to the SILVA v119 database, removed sequences which did not overlap with the same region of the $16 \mathrm{~S}$ rRNA gene after alignment, and fixed the maximal allowed homopolymer length at 8 . Overhangs at both ends of the aligned sequences were filtered out after which we pre-clustered sequences allowing for up to two nucleotide difference between them. We subsequently removed all chimeric sequences. The remaining set of filtered sequences was assigned to taxonomic groups using the Bayesian classifier with a confidence threshold of $60 \%$ using the SILVA v119 database. This allowed us to remove all sequences corresponding to gene fragments of chloroplasts, mitochondria, Archaea and eukaryotes and to cluster the retained bacterial sequences into OTUs based on $97 \%$ identity cutoff. Rarefaction curves were generated with randomizations of 1000 and increments of 1000 sequences using mothur and plotted in Microsoft Excel 2010. The final OTU table was rarefied at 4448 reads, which reduced the number of OTUs from 1086 to 718 and was used for all downstream analyses. Kruskal-Wallis and post hoc MannWhitney tests were used to evaluate significance of individual OTU abundance changes between different developmental stages of the ants. Inverse Simpson indices were estimated in mothur and plotted in JMP 11 to characterize compositional complexity of bacterial communities. To compare the similarity of bacterial community profiles, we performed ordination analysis [non-metric multidimensional scaling (NMDS)] of Bray-Curtis dissimilarity indices, unweighted and weighted UniFrac distances and permutational multivariate analysis of variance (PERMANOVA, permutation number $=9999$ ) in PAST3. Bray-Curtis indices were also calculated in PAST3, while UniFrac distances were computed in mothur.

To compare Mollicutes density in the transmission experiment, we ran a negative binomial regression model for the ddPCR counts in R ( $\mathrm{R}$ Core Team, 2016), because negative binomial models show a good fit to overdispersed data. Using a Tukey contrast matrix and Bonferroni correction, post hoc pairwise tests were run to determine significant differences across four sampling groups ("pupae," "callows+workers on day 1 ," "callows + workers on day 21 ," "isolated callows on day 21 ") in each experiment with combination of colonies (Ae360 + Ae360, Ae507 + Ae322, Ac2012-2 + Ac2012-3, Ac2012-3 + Ac2012-2; see above for details about these combinations). If there were many zero counts, zero-inflated, hurdle and negative binomial regression models were tested and the Akaike's Information Criterion (AIC) was calculated for each of them to select the most appropriate model, which always turned out to be a negative binomial or hurdle model. To compensate for the complete separation problem in some colonies where concentrations of bacteria in pupae were zero for all individuals, we ran binomial-response generalized linear models using the bias-reduction method developed by Firth (1993). In this procedure, we first compared the "pupae" to the other three groups ("callows+workers on day 1," "callows+workers on day 21 ," "isolated callows on day 21 ") to investigate whether the pupal stage differed from the other three groups by a presence/absence parameter $(1 / 0)$, and we then removed the pupal stage from our dataset and ran a negative binomial or hurdle model, as described above.

\section{Microscopy}

For fluorescence in situ hybridization (FISH), five ant workers, larvae and pupae from A. echinatior colony Ae507 and A. cephalotes colony 2012-2 were dissected in PBS and their guts placed in $4 \%$ paraformaldehyde overnight. For the permeabilization, deproteinization, and hybridization, we followed a previously described protocol (López-Madrigal et al., 2013). For the hybridization step, we used $0.75 \mu \mathrm{g} / \mu \mathrm{l}$ specific labeled probes targeting bacteria belonging to the class Mollicutes (order Entomoplasmatales) and Wolbachia-specific probes (Supplementary Table S1). As negative controls, we used water and reverse probes for Mollicutes (Supplementary Table S1). As positive control, we used the universal bacterial probe EUB388 (Amann et al., 1990) for the pupal stage, because there was no interfering autofluorescence coming from food particles in the gut. The samples were inspected and photographed using a Zeiss LSM 710 confocal microscope equipped with ZEN 2009 software and a Leica TCS SP2 microscope. We considered a signal as being specific when it was absent from the negative controls and colocalized with blue spots produced by simultaneous DAPI staining of bacterial DNA.

For transmission electron microscopy (TEM), larvae, pupae, and large workers of A. echinatior colony Ae507 and media workers of $A$. cephalotes colony 2012-2 were dissected in $0.01 \mathrm{M}$ phosphate buffer ( $\mathrm{pH} 7.4$ ), and guts were fixed in $2.5 \%$ glutaraldehyde (Sigma) in $0.1 \mathrm{M}$ sodium cacodylate buffer $(\mathrm{pH}$ 7.4) for $2.5 \mathrm{~h}$. This was followed by washings in the same buffer and postfixation in $1 \%$ OsO4 for $1 \mathrm{~h}$, after which samples were placed in a $1 \%$ aqueous solution of uranyl acetate and left at $4^{\circ} \mathrm{C}$ overnight. Samples were then dehydrated in an ethanol series and acetone and embedded in Spurr low-viscosity resin (Ted Pella Inc.). Ultrathin sections of 60-70 nm thickness were stained with uranyl acetate and Reynolds lead citrate and examined with a transmission electron microscope (JEM 1010, JEOL).

\section{RESULTS}

\section{Quantitative Analysis of Bacterial Density}

Densities of bacterial 16S rRNA gene copies (Figure 1A) were differentially distributed among the two leaf-cutting ant species (Kolmogorov-Smirnov test, $p=0.0001$ ). In Acromyrmex, there was no significant difference among the three developmental stages (Kruskal-Wallis test, $p=0.096$ ), but there was a significant difference among the same developmental stages in Atta (Kruskal-Wallis test, $p=0.0013$; post hoc Mann-Whitney test: larvae-pupae: $p=0.0102$, pupae-workers: $p=0.002)$. Gene copy numbers were similar in larvae and pupae of $A$. echinatior, with median densities of 1.79 and 1.43 copies per host cell, respectively, but less in Atta larvae (with a median of 0.14) and the lowest density in Atta pupae (0.067 copies per cell). The highest bacterial densities were observed in workers of 
both species (median 3.65 copies per cell in $A$. echinatior and 37.7 in $A$. cephalotes) and without a significant difference between workers of these two species (Mann-Whitney test, $p=0.59$ ). However, bacterial cell numbers were always bimodally distributed across worker samples, with numbers ranging from 0.07 to 222 bacteria per host cell in $A$. cephalotes and from 0.82 to 114 in A. echinatior.

\section{Community Composition of Gut Bacteria Based on 16S rRNA Miseq Sequencing}

A total of 31 bacterial classes and 470 OTUs (97\% sequence identity cut-off) were identified across the gut communities of A. echinatior (12 classes were present in abundances exceeding $1 \%$ in at least one individual) and 32 bacterial classes and 374 OTUs were found across the gut communities of $A$. cephalotes (21 exceeding the 1\% abundance threshold, Supplementary Table S2). The rarefaction curves approached asymptotes indicating that sufficient sampling depth was achieved for all samples (Supplementary Figure S1). The diversity of bacteria was very low in Acromyrmex pupae and adults (inverse Simpson indices close to 1, Figure 1B), whereas Acromyrmex larvae harbored a higher bacterial diversity (mean inverse Simpson index $=2.3$; range 1.01-10.25). Gut bacterial diversity in Atta appeared to be very different, with highly diverse pupal gut microbiomes (mean inverse Simpson index $=6.6$; range $1.24-$ 20.11 ) and moderately high diversity in both larvae ( mean $=3.82$; range $1.5-6.76$ ) and adults (mean $=2.55$; range $1.00-7.87$ ) (Figures 1B, 2). Diversity measures were negatively correlated with overall bacterial abundance in A. cephalotes (Kendall's rank correlation, $\tau=-0.56, p=0.00002$ ), but not in A. echinatior $(\tau=-0.14, p=0.24)$, suggesting the presence of dominant bacterial OTUs (when inverse Simpson index close to 1) leads to an increase of overall bacterial abundance in A. cephalotes, but not in A. echinatior (where a dominant OTU was present in almost all individuals analyzed). Overall, nMDS plots generated from a Bray-Curtis dissimilarity matrix revealed two non-overlapping clusters for $A$. echinatior and A. cephalotes (Supplementary Figure S2A) and all performed statistical tests of community structure (PERMANOVA) showed a highly significant difference in OTU composition and relative abundances between the two leaf-cutting ant species (Supplementary Table S3).

In $A$. echinatior the most prevalent OTU was a Wolbachia, comprising an average of $76.0,91.6$, and $74.9 \%$ of the gut bacteria in larvae, pupae and workers, respectively, whereas the most abundant OTU in A. cephalotes belonged to the Mollicutes and reached average abundances of $17.2,21.6$, and $81.3 \%$ in the guts of larvae, pupae and workers, respectively. However, this only applied to two colonies because the third colony had low $(<0.05 \%)$ infections in only two individuals and was thus considered to be Mollicutes-uninfected (Figure 2). We confirmed that this abundant OTU was identical to the one we identified as EntAcro1 across workers from six species of Panamanian Atta and Acromyrmex leaf-cutting ants (Sapountzis et al., 2015; Sapountzis et al., in revision). One of the four colonies of $A$. echinatior (Ae715) also had high gut infection levels with EntAcro1 (on average $85.5 \%$ of all reads, Figure 2 ).
In larvae of $A$. echinatior, several OTUs in addition to the dominant Wolbachia OTU reached relative abundances of more than $10 \%$ in at least one individual (Enterobacteriaceae, Lactobacillus 2, Bacteroidales 1 and 2) and other OTUs hovered between 3 and $10 \%$ in several individuals [Pseudomonas, Pelomonas, Pseudonocardia (99\% identical to the Ps1 and Ps2 A. echinatior symbiont; Andersen et al., 2013), Lactobacillus 1, Turicibacter, Bacteroidales 2] (Figure 2). Larvae of A. cephalotes had a relatively high abundance of Enterobacteriaceae $(25.6 \%$ on average across all sequence reads), Pseudomonas 1 (12.7\% on average) and Pseudomonas 2 (69.8\% in one individual). Atta guts also harbored rather many OTUs present in several individuals with abundances below 10\% (Pelomonas, Ralstonia, Janthinobacterium, Acinetobacter, Sphingobium) and with abundances of more than $10 \%$ but occurring in just one sample (Lactobacillus 2, Pseudonocardiaceae, Bacteroidales, Bacillus, Bacteroides, Ruminococcus, Verrucomicrobia, Prevotellaceae). Only OTUs belonging to the Enterobacteriaceae and Pseudomonas were present in both A. echinatior and A. cephalotes larvae.

Pupal gut communities of $A$. echinatior were once more dominated by Wolbachia, but also included a Pseudomonas OTU that was found in the preceding larval stage. All pupal guts of colony A715, which was highly infected with EntAcrol in the adult stage, had OTUs that were not identified in other stages of development (Bacteroides and Akkermansia). In A. cephalotes, most prevalent pupal gut OTUs were also present in larval guts (EntAcro1, Enterobacteriaceae, Pseudomonas 1 and 2, Pelomonas, Ralstonia, Janthinobacterium, Acinetobacter, Pseudonocardia, and Sphingobium), although the relative abundance of Enterobacteriaceae significantly decreased in the pupal stage in comparison to larval guts (Mann-Whitney test, $p=0.002$ ). There were also some unique pupal OTUs, which were present in abundances of more than $10 \%$ of the total reads in at least one individual (e.g., Methylobacillus, Micrococcus, and Methylobacterium) and that did not appear in other developmental stages (Figure 2).

The adult worker gut community of $A$. echinatior was completely dominated by Wolbachia and EntAcro1, which jointly accounted for $97-99.8 \%$ of the total number of reads per individual. Bacterial diversity of gut communities of $A$. cephalotes workers varied depending on the colony's infection with EntAcro1. When colonies were infected by these Mollicutes bacteria, they represented $89-99.9 \%$ of all sequence reads for separate individuals. However, there were some EntAcro1uninfected workers, and these uninfected workers had more diverse gut microbial communities, including both specific for this stage OTUs (e.g., two Rhizobiales OTUs, Staphylococcus) and OTUs that were present also in larvae and pupae (e.g., Pseudomonas, Pelomonas). Rhizobiales, Pseudomonas, Pelomonas, Staphylococcus, Chryseobacterium, Cyanobacteria, and Lactococcus occurred in abundances of more than $10 \%$ of all reads at least in one individual. Overall, Atta workers had either very few bacteria in their guts and then their microbiomes were relatively diverse, or they had many and then gut bacteria were almost exclusively Mollicutes. When we compared abundances of 16S rRNA gene copy numbers for workers with proportional 

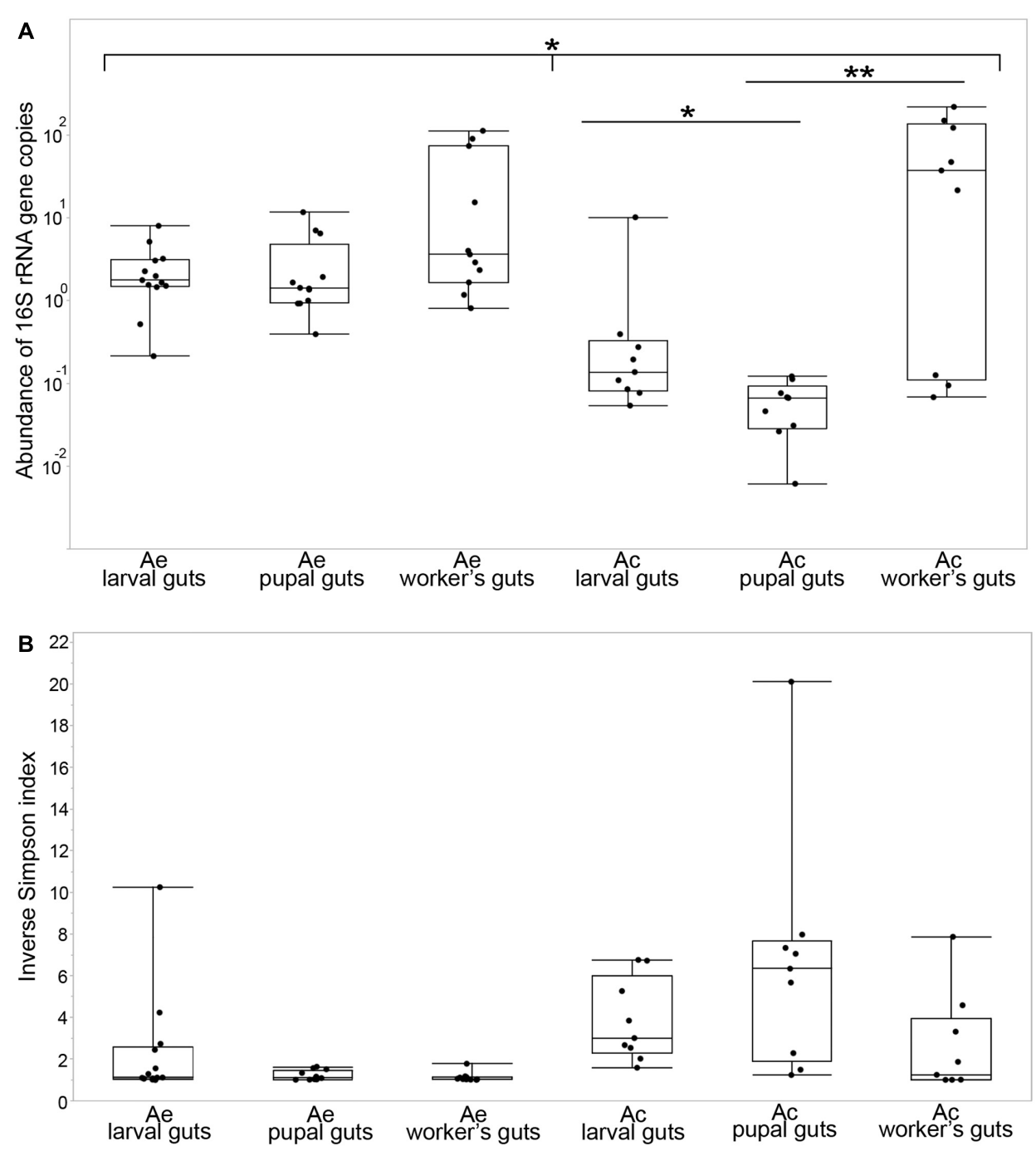

FIGURE 1 | Density and diversity of the gut bacterial communities across the different developmental stages of Acromyrmex echinatior (Ae) and Atta cephalotes (Ac) leaf-cutting ants. (A) Plotted are densities of bacteria (relative abundances of bacterial 16S rRNA gene copies per host cell measured with ddPCR) in the guts of individual larvae, pupae, and adult workers sampled from field colonies. Bars above plots highlight significant differences based on Kolmogorov-Smirnov test for equal distributions between two species and Kruskal-Wallis and post hoc Mann-Whitney tests for developmental stages within each species: * $p \leq 0.05$, ${ }^{* *} p \leq 0.01$. (B) Each point represents the inverse Simpson index of bacterial alpha diversity for a sample collected from an individual (larva, pupa, or adult). Central lines of boxplots are medians, the upper and lower limits of boxes are 75th and 25th quantiles and whiskered bars are minimal and maximal values.

presences of Mollicutes $<0.1 \%$ and $>0.1 \%$, the latter mean absolute number of bacteria was $>20$ times higher in Atta, but only 3.4 times higher, and not significantly so, in Acromyrmex (Supplementary Figure S3, Mann-Whitney test, A. echinatior: $p=0.219$, A. cephalotes: $p=0.019)$.

\section{Analyses of Beta Diversity across Developmental Stages}

We used a PERMANOVA test to evaluate the similarity of gut communities across the larval, pupal, and adult stages (Supplementary Table S3). For A. echinatior we found a significant difference in beta diversity between both developmental stages and the colonies sampled, and also a significant stage $\times$ colony interaction in all tests performed (using Bray-Curtis dissimilarities, unweighted and weighted UniFrac metrics). The nMDS plots revealed close similarity between the two colonies with dominant Wolbachia infections across all developmental stages (Ae711 and Ae712), whereas all stages of the colony with dominant EntAcro1 (Ae715) had a different bacterial community, and also the larvae of colony Ae717 with high bacterial diversity and low Wolbachia titer stood out (Supplementary Figure S4). For A. cephalotes we found a significant difference, both between colonies and developmental stages (Supplementary Figures S5, S6) in all tests performed, but no significant stage $\times$ colony interaction was found in tests performed on either Bray-Curtis dissimilarities or weighted UniFrac distances (Supplementary Table S3). Pairwise differences in beta diversity were significant between 

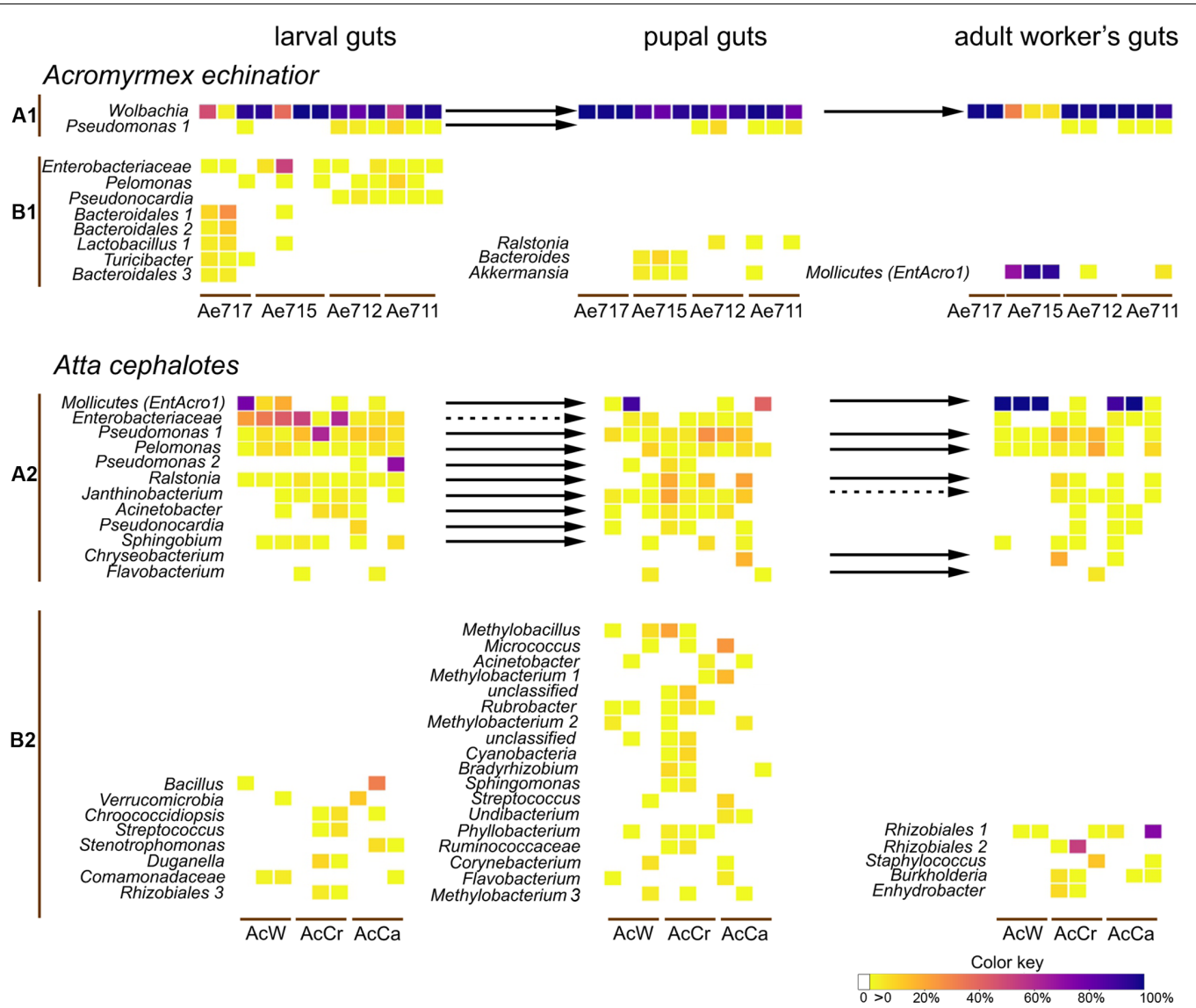

FIGURE 2 | The relative abundances of the main OTUs obtained from the individual gut samples of four $A$. echinatior colonies and three $A$. cephalotes colonies. The top heatmaps for each species (A1,A2) include OTUs that were present in at least two developmental stages (connected by arrows when both prevalences exceeded $3 \%$ ), and the bottom heatmaps (B1,B2) give the stage-specific OTUs that were present in at least two individuals (and exceeded $3 \%$ relative abundance in at least one individual). Solid arrows designate transitions of bacteria between developmental stages without substantial change in relative abundance while dashed arrows are bacterial transmissions with significant decreases of relative abundance in Mann-Whitney tests $(p<0.05)$.

larvae and workers of $A$. cephalotes $(p=0.0291)$ and between Mollicutes-infected (AcW) and uninfected $(\mathrm{AcCr})$ colonies $(p=0.0021)$ in Bray-Curtis index comparisons, but there was no significant difference between groups in tests with weighted UniFrac distances (Supplementary Table S4).

\section{Transovarial Transmission for Wolbachia But Not for Mollicutes}

Assuming that transmission mechanisms of dominant bacteria are similar in field and lab colonies, we tested the presence of Wolbachia and Mollicutes in A. echinatior and A. cephalotes lab colonies by PCR and included also eggs in the analysis (Table 1 and Supplementary Table S5). Wolbachia was always present in worker guts of A. echinatior, but never in Atta. EntAcro1 and EntAcro2 OTUs were universally found in worker guts of both A. echinatior and A. cephalotes, either in single or double-infections. Wolbachia bacteria were present in the eggs of all Acromyrmex colonies and remained present in all developmental stages (Supplementary Table S5). However, the Mollicutes were absent in the eggs of all three Acromyrmex and all four Atta colonies (Table 1). Mollicutes were present in very low abundance in guts of some larvae of both ant species, but were detected just once in the gut of a pupa of A. echinatior, which is similar to the pattern observed in the field colonies (Supplementary Table S6). It is noteworthy that Mollicutes were sometimes found in the remaining bodies of dissected pupae from field and lab colonies, even though the guts of the same pupae were most often uninfected (Table 2 and Supplementary Table S7). Finally, Mollicutes were present in the guts of some, but not all adult workers of both A. echinatior and A. cephalotes.

Microscopy of the lab colony of A. echinatior showed that Wolbachia bacteria were present in the epithelial cells of the larval gut (Supplementary Figures S7A,B) and in all pupal gut compartments (crop, midgut, ileum, and rectum), but seldom in the pupal Malpighian tubules (Supplementary Figures S7C-G). Some Wolbachia bacteria were in close contact with mitochondria in pupal and adult tissues (Supplementary Figures S7H,I). We could not localize Mollicutes in larval and pupal guts from the lab colony of A. cephalotes, confirming that bacterial presence (including Mollicutes) in these stages is very low (Figures $\mathbf{3 A}, \mathbf{D})$. Nevertheless, there were a 

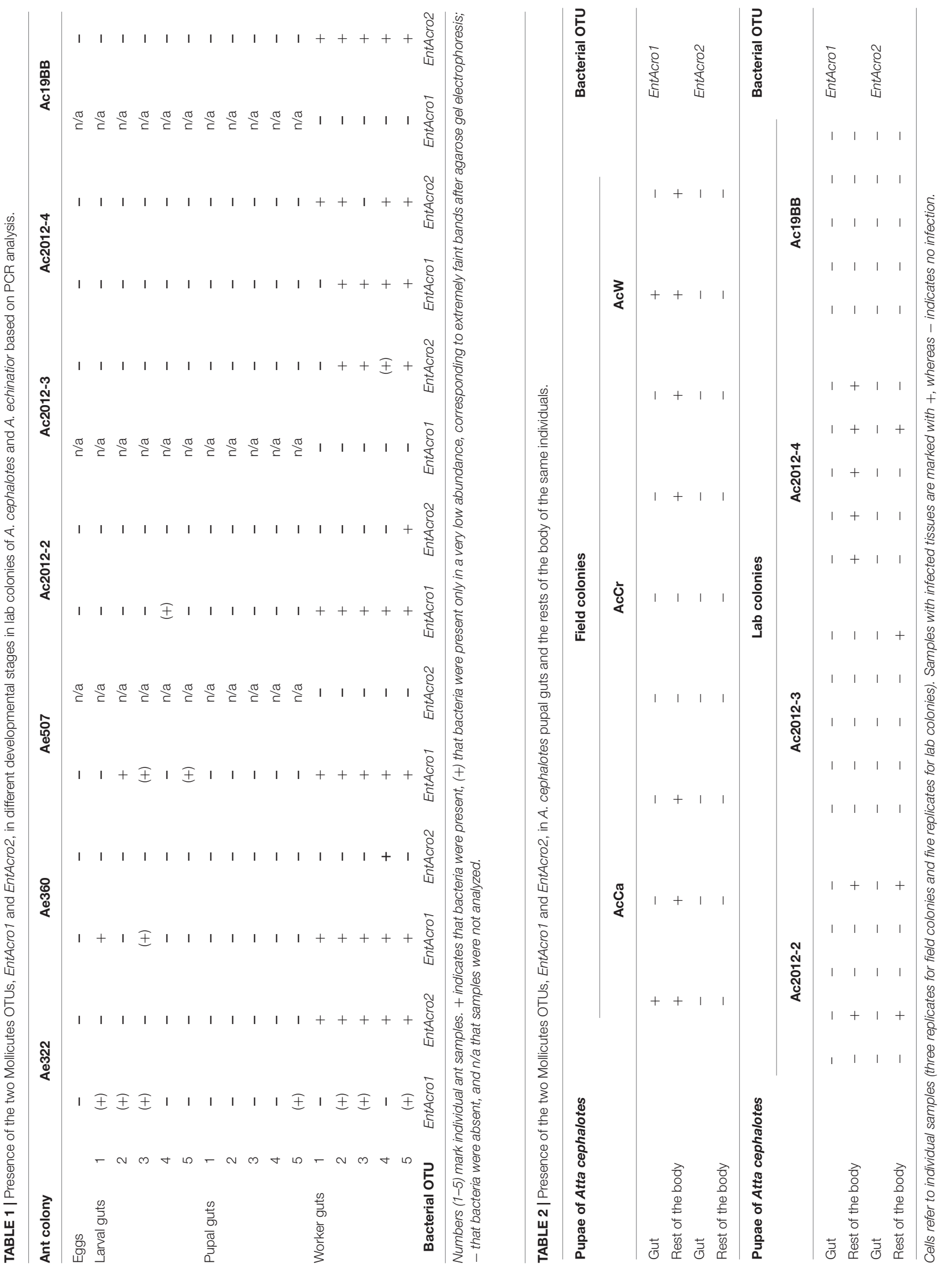
few Gram-negative bacteria in the gut lumen of larvae of A. cephalotes, mixed with homogenous food (Figures $3 \mathbf{B}, \mathbf{C}$ ), suggesting that larvae acquired them with the ingested fungus. However, Mollicutes were highly abundant in the rectum of adult $A$. cephalotes workers supporting our quantitative ddPCR data (Figure 3E). The Mollicutes-like bacteria that we observed with TEM lacked a cell wall, which is a unique feature of Mollicutes, and had rod shapes with an average diameter $0.4 \mu \mathrm{m}$ and a length range of $0.7-1.9 \mu \mathrm{m}$ (Figure 3F).

\section{Test of the Hypothesis of Social Transmission for Mollicutes}

Before the bacterial transmission experiment (Figure 4A), we tested Mollicutes infection status in workers from the lab colonies. We found that EntAcro1 had displaced EntAcro2 in most colonies that we analyzed (Supplementary Table S8) during a 9 months period that had passed since our previous check (Table 1). Measurement of Mollicutes density with sensitive ddPCR technology confirmed that both EntAcro1 and EntAcro2 were absent or had very low density in mature pupae (medians below 0.01 16S rRNA gene copies per gut host cell in all colonies, Figure 4B). After 21 days in isolation, no workers $(n=20$, checked for both EntAcro1 and EntAcro2) showed an increase in density of Mollicutes in their guts and often the density was similar to that of pupae, implying that bacteria do not reinfect and multiply in the gut of workers from adjacent tissues after eclosion. In contrast, many of the workers that had been in contact with other workers for 21 days after eclosion, showed a significant increase in Mollicutes density, suggesting that interaction with workers in the absence of fungus garden is enough for Mollicutes transmission between ants from the same or different colonies.

\section{DISCUSSION}

\section{Diversity and Density of Gut Bacteria during Different Developmental Stages}

Like other Hymenoptera, ants undergo complete metamorphosis, in which larvae stop feeding and purge their gut before pupation. During metamorphosis larval gut epithelium undergoes programmed cell death and is replaced by pupal/adult epithelium. In the gut, the pupa stores metabolic wastes as a meconium which is excreted when the adult hatches. The complete remodeling of the gut thus provides great opportunities to change gut bacterial communities across developmental stages, and this flexibility may be especially important for species in which larvae and adults have different diets and lifestyles. So far, very few other studies on social insects have provided evidence for distinct microbial community differences between larval and worker guts. Enterobacter and Pseudomonas, dominant bacteria of the fungus gardens in both A. cephalotes and A. echinatior (Aylward et al., 2014), were found in larval guts, but disappeared in workers of $A$. echinatior or remained present only at highly reduced abundances in A. cephalotes. Representatives of several bacterial families
[Bacillaceae, Burkholderiaceae (Ralstonia), Comamonadaceae, Flavobacteriaceae, Moraxellaceae, Sphingomonadaceae] were also observed in the fungus garden of Atta species (Suen et al., 2010; Aylward et al., 2012) and bacterial OTUs that we found in larval guts (Bacillus, Ralstonia, Pelomonas, Chryseobacterium, Flavobacterium, Acinetobacter, and Sphingobium) belong to the same families. This suggests that the fungus garden plays an important role in supporting the persistence of these bacteria within colonies, but further study will be required to fully understand their beneficial role for larvae or fungus gardens. The few Pseudonocardia bacteria that were present in larval guts of $A$. echinatior (with relative abundance ranging from 0.07 to $3.2 \%$ ) could come from the cuticle of the workers feeding them or from the fungus garden assuming workers would inoculate these as well. Studies of bee species have shown that honey bee larvae harbor both bacteria belonging to the core gut microbiome of adults and other OTUs that potentially originate from nectar sources (Mohr and Tebbe, 2006; Vojvodic et al., 2013), while bumblebee larvae have gut bacteria of adults but in different proportion (Mohr and Tebbe, 2006).

Despite the fact that larvae purge the gut before pupation, bacteria have been found in pupae of insects from various orders: Coleoptera (Delalibera et al., 2007), Diptera (Wong et al., 2011), Lepidoptera (Hammer et al., 2014; Johnston and Rolff, 2015), and Hymenoptera (Brucker and Bordenstein, 2012). In our study, the bacterial load was very low in mature pupae of A. cephalotes, implying that metamorphosis resulted in nearcomplete elimination of gut bacteria, but in $A$. echinatior the bacterial load did not decrease relative to the larval stage and Wolbachia accounted for $>90 \%$ of the overall abundance of pupal gut bacteria. In some insects, bacteria in the pupal gut determine the adult gut microbiota (Johnston and Rolff, 2015), while others acquire gut bacteria after metamorphosis from their food and environment (Engel and Moran, 2013). Our data suggest that adult workers of both leaf-cutting ant species lose most of the bacteria present in the early developmental stages and re-establish the adult gut microbiota after eclosion.

\section{Mollicutes Social Transmission Patterns}

Our results matched the expectation that Wolbachia are maternally inherited bacteria, as shown for solitary insects (e.g., Serbus et al., 2008), but Mollicutes were absent in eggs of all leaf-cutting ants that we investigated. Previous studies in the army ant Eciton burchellii likewise did not find Entomoplasmatales bacteria in eggs, whereas in the fungusgrowing ant Sericomyrmex amabilis, Entomoplasmatales were found sporadically (in 4 of 10 eggs from one colony) (Funaro et al., 2011; Liberti et al., 2015). Some larvae of $A$. cephalotes from the field and $A$. echinatior from the lab had Mollicutes in their guts. In army ants, Entomoplasmatales occurred sporadically in larvae of E. burchellii and pupae of Dorylus molestus, but were absent in most larvae and pupae of other species analyzed (Funaro et al., 2011). In both Atta and Acromyrmex species workers play a major role in feeding the larvae. In Acromyrmex subterraneus brunneus, workers macerate fungal staphylae by mandibular movements before feeding them to larvae (Camargo et al., 2006), while workers of Atta sexdens deposit the fungal 

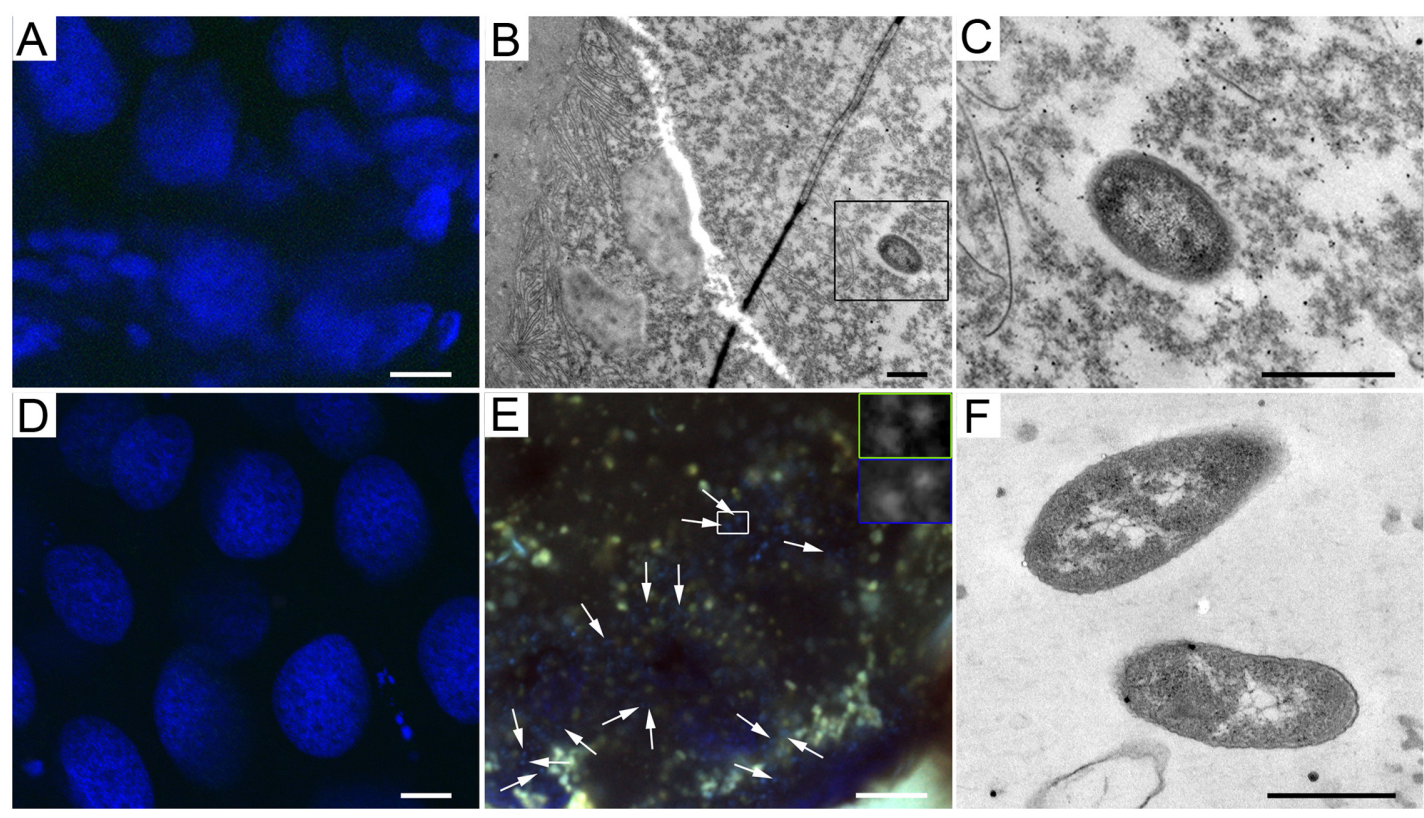

FIGURE 3 | Mollicutes bacteria in A. cephalotes across developmental stages. (A,D) Absence of Mollicutes in larval (A) and pupal (D) tissues of A. cephalotes. (B) Gram-negative bacterium in the lumen of a larval gut of $A$. cephalotes. (C) Higher magnification of the bacterium framed in B. (E) Highly abundant Mollicutes in a worker's rectum of $A$. cephalotes (arrows point at some of the bacteria). Frames show bacteria stained with a Mollicutes-specific probe (framed green) and DAPI (framed blue) at higher magnification. (F) Mollicutes-like bacteria lacking a cell wall in the rectum of $A$. cephalotes worker. Scale bars are $10 \mu \mathrm{m}$ (A,D,E) and $0.5 \mu \mathrm{m}$ $(B, C, F)$.

mass, prepared with other mouthparts than the mandibles, directly on a larva's mandibles (Schneider et al., 2000). Although other details may differ, this broad similarity in feeding behavior suggests that transmission of Mollicutes to larval guts can happen through active feeding in both species. Pupal guts of Acromyrmex and Atta occasionally had Mollicutes, while the remaining part of the body carried these bacteria more often. Previous studies have shown that Mollicutes can be both intracellular and extracellular symbionts in ants, and some bacteria of the same order were also isolated from the hemolymph of a firefly beetle (Tully et al., 1989; Sapountzis et al., 2015). We thus hypothesize that Mollicutes bacteria infect hemolymph and surrounding tissues of leaf-cutting ants during remodeling of the internal anatomy in the pupal stage, but further work will be needed to substantiate this.

In some solitary insects, Mollicutes increase longevity and fecundity of their vector hosts (Ammar and Hogenhout, 2006), but it remains as yet unclear whether and how Mollicutes (EntAcro1 and EntAcro2) are beneficial for Acromyrmex and Atta leaf-cutting ants. In the adult workers, the Mollicutes were most abundant in the rectum, suggesting that this is the most favorable niche for them. Both Acromyrmex and Atta also maintain Rhizobiales bacteria, which have nitrogen fixing/preservation functions and form a biofilm adhering to the cuticle in the ileum and rectum of workers (Sapountzis et al., 2015; Sapountzis et al., in revision), but there is no direct evidence that Rhizobiales compete with Mollicutes for host resources in the rectum. Mollicutes are also increasingly documented to be widespread among ant species, with recent studies having demonstrated their presence in workers of Solenopsis species, Ponerinae ants, turtle ants, and Atta texana (Ishak et al., 2011; Kautz et al., 2013; Meirelles et al., 2016; de Oliveira et al., 2016). Our experiments clearly indicate that Mollicutes are transmitted through social interactions between workers. Social transmission of bacteria has also been shown for other social insects, such as honeybees and bumblebees (Martinson et al., 2012; Billiet et al., 2017). These findings suggest that Mollicutes may be a generally underappreciated lineage of symbionts across the ants that would be interesting for further studies.

\section{Putative Functions of Bacterial Gut Symbionts in Leaf-Cutting Ants}

The unique lifestyle of social insects allows certain types of specialized bacteria to become established and be transmitted within colonies that would not be able to maintain themselves as symbionts of solitary insects. Our results reveal at least two different pathways by which bacterial OTUs can persist within leaf-cutting ant colonies and indicate that unraveling the stages of bacterial acquisition gives useful information about the putative mutualistic functions of symbionts across developmental stages. This is particularly so for the socially transmitted Mollicutes symbionts (EntAcro1 and EntAcro2), which showed enormous variation in abundance both across and within colonies of A. echinatior and A. cephalotes. Although these bacteria are mostly known as mild pathogens (Meirelles et al., 2016), such antagonistic functions seem highly unlikely for the EntAcro1 and EntAcro2 symbionts of leaf-cutting ants because 

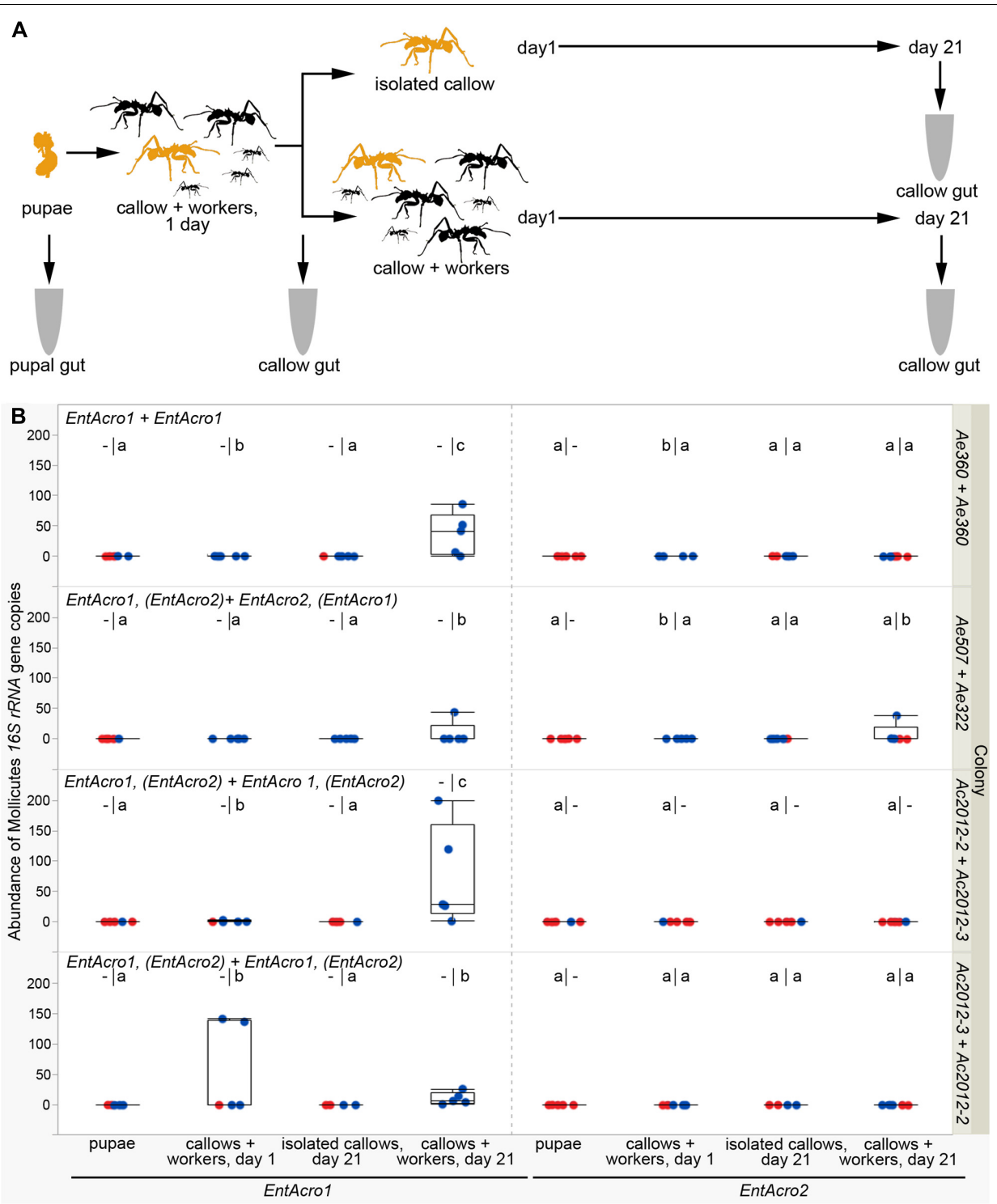

FIGURE 4 | Acquisition of Mollicutes bacteria by workers after hatching. (A) Schematic diagram of the experiment. Pupae and newly emerged workers are colored in yellow, while major and minor ants from the paired colony are shown in black. Guts of pupae and callows were sampled for analyses. (B) Density of Mollicutes expressed as 16S rRNA gene copies normalized per gut cell number. The first Mollicutes OTUs above each plots correspond to the known infections of the colony from which pupae were taken and the second (after the +) to the known infections of the nursing workers that interacted with callows emerging from these pupae (in brackets when Mollicutes were not present in all tested workers or were present in low abundances; for more information see Supplementary Table S8). Red dots correspond to bacterial scores of zero, while blue dots are scores above zero. The lower-case letters above each boxplot indicate significant differences between groups resulting from two different statistical tests. On the left side, different letters indicate significant differences $(p<0.05)$ in binomial $(1 / 0=$ presence/absence) tests (performed only in colonies where the "pupae" group had all zero scores and this group was omitted from further analysis). On the right side, different letters indicate significant differences $(p<0.05)$ in bacterial densities between groups in post hoc pairwise multiple comparisons. - indicates that a corresponding test was irrelevant or could not be performed.

we never observed any disease symptoms in ants that were later shown to carry Mollicutes in high abundances. However, these bacteria are clearly facultative symbionts across the leafcutting ants, so further work to clarify their functions will be rewarding.

When we combine the findings of our present studies with earlier results (Frost et al., 2010; Andersen et al., 2012; Sapountzis et al., 2015), it appears that Wolbachia is an obligate symbiont throughout the developmental stages of Acromyrmex leaf-cutting ants. The symbiotic function of these bacteria remains enigmatic, but their abundant presence and close interaction with mitochondria in the ant cytoplasm corroborate that Wolbachia is a highly adapted symbiont and worth further study to clarify its functions both in the larval and adult stages.

In this first systematic study of bacterial symbionts of ant brood, we found that both Enterobacter and Pseudomonas 
bacteria were relatively abundant in larval guts and hardly present in adult worker guts. We suggest that these bacteria may be involved in immune priming, and suggest that further work in this direction may be worthwhile. It has been shown that larvae of both social and solitary insects, including carpenter ants Camponotus pennsylvanicus, tiger moths Parasemia plantaginis, and cabbage semilooper Trichoplusia ni, all exhibit immune priming (Freitak et al., 2007; Rosengaus et al., 2013; Mikonranta et al., 2014), making larvae less susceptible to pathogens after both oral exposure to non-pathogenic and pathogenic bacteria and injection with killed pathogenic bacteria.

\section{ETHICS STATEMENT}

The research project was conducted on invertebrate species that are not subjected to any specific ethical issue and legislation. The Autoridad Nacional del Ambiente de Panama (ANAM) issued permits for collection and export of live and frozen ant material from Panama to Denmark (2014).

\section{AUTHOR CONTRIBUTIONS}

MZ and JB carried out the field sample collection, MZ and PS performed the experiments and data analysis. MZ, PS, MS, and JB designed the study, drafted and wrote the manuscript. All authors read and approved the final manuscript.

\section{REFERENCES}

Amann, R. I., Binder, B. J., Olson, R. J., Chisholm, S. W., Devereux, R., and Stahl, D. A. (1990). Combination of 16S rRNA-targeted oligonucleotide probes with flow cytometry for analyzing mixed microbial populations. Appl. Environ. Microbiol. 56, 1919-1925.

Ammar, E.-D., and Hogenhout, S. (2006). "Mollicutes associated with arthropods and plants," in Insect Symbiosis, Vol. 2, eds K. Bourtzis and T. A. Miller (Boca Raton, FL: CRC Press), 97-118. doi: 10.1201/9781420005936.ch6

Andersen, S. B., Boye, M., Nash, D. R., and Boomsma, J. J. (2012). Dynamic Wolbachia prevalence in Acromyrmex leaf-cutting ants: potential for a nutritional symbiosis. J. Evol. Biol. 25, 1340-1350. doi: 10.1111/j.1420-9101. 2012.02521.x

Andersen, S. B., Hansen, L. H., Sapountzis, P., Sørensen, S. J., and Boomsma, J. J. (2013). Specificity and stability of the Acromyrmex-Pseudonocardia symbiosis. Mol. Ecol. 22, 4307-4321. doi: 10.1111/mec.12380

Aylward, F. O., Burnum, K. E., Scott, J. J., Suen, G., Tringe, S. G., Adams, S. M., et al. (2012). Metagenomic and metaproteomic insights into bacterial communities in leaf-cutter ant fungus gardens. ISME J. 6, 1688-1701. doi: 10.1038/ismej. 2012.10

Aylward, F. O., Suen, G., Biedermann, P. H. W., Adams, A. S., Scott, J. J., Malfatti, S. A., et al. (2014). Convergent bacterial microbiotas in the fungal agricultural systems of insects. mBio 5:e02077-14. doi: 10.1128/mBio.02077-14

Ben-Yosef, M., Pasternak, Z., Jurkevitch, E., and Yuval, B. (2015). Symbiotic bacteria enable olive fly larvae to overcome host defences. $R$. Soc. Open Sci. 2:150170. doi: 10.1098/rsos.150170

Billiet, A., Meeus, I., Van Nieuwerburgh, F., Deforce, D., Wäckers, F., and Smagghe, G. (2017). Colony contact contributes to the diversity of gut bacteria in bumblebees (Bombus terrestris). Insect Sci. 24, 270-277. doi: 10.1111/17447917.12284

\section{FUNDING}

The project was supported by funding from the European Union's Horizon 2020 research and innovation program under the Marie Sklodowska-Curie grant agreement no. 660255, and by the ERC Advanced Grant (323085) of JB.

\section{ACKNOWLEDGMENTS}

We thank the University of Michigan Host Microbiome Initiative (HMI) for the library preparation and advice about Miseq sequencing, Sarah Cherasse, Ryan Dosselli, and Madlen Kratz for help during the fieldwork, Anders Garm for access to the confocal microscope, Øjvind Moestrup for access to the transmission electron microscope, Sylvia Mathiasen for lab assistance, and Luigi Pontieri and David Nash for help with the statistics. The TEM work was performed at the facilities of the Center for Advanced Bioimaging (CAB), University of Copenhagen. The Smithsonian Tropical Research Institute in Panama provided lab facilities during fieldwork, and the Autoridad Nacional del Ambiente of Panama issued collection and export permits.

\section{SUPPLEMENTARY MATERIAL}

The Supplementary Material for this article can be found online at: https://www.frontiersin.org/articles/10.3389/fmicb. 2017.01942/full\#supplementary-material

Boomsma, J., Schmid-Hempel, P., and Hughes, W. O. H. (2005). "Life histories and parasite pressure across the major groups of social insects," in Insect Evolutionary Ecology, eds M. Fellowes, G. Holloway, and J. Rolff (Wallingford: CABI Publishing), 139-175. doi: 10.1079/9780851998121.0139

Braig, H. R., Zhou, W., Dobson, S. L., and O'Neill, S. L. (1998). Cloning and characterization of a gene encoding the major surface protein of the bacterial endosymbiont Wolbachia pipientis. J. Bacteriol. 180, 2373-2378. doi: 10.1099/ 0022-1317-69-1-35

Bright, M., and Bulgheresi, S. (2010). A complex journey: transmission of microbial symbionts. Nat. Rev. Microbiol. 8, 218-230. doi: 10.1038/ nrmicro2262

Brucker, R. M., and Bordenstein, S. R. (2012). The roles of host evolutionary relationships (genus: Nasonia) and development in structuring microbial communities. Evolution 66, 349-362. doi: 10.1111/j.1558-5646.2011. 01454.x

Camargo, R. S., Forti, L. C., Lopes, J. F. S., and Andrade, A. P. P. (2006). Brood care and male behavior in queenless Acromyrmex subterraneus brunneus (Hymenoptera: Formicidae) colonies under laboratory conditions. Sociobiology $48,717-726$.

de Oliveira, T. B., Ferro, M., Bacci, M., Souza, D. J., de, Fontana, R., et al. (2016). Bacterial communities in the midgut of ponerine ants (Hymenoptera: Formicidae: Ponerinae). Sociobiology 63, 637-644. doi: 10.13102/sociobiology. v63i1.882

Delalibera, I. J., Vasanthakumar, A., Burwitz, B. J., Schloss, P. D., Klepzig, K. D., Handelsman, J., et al. (2007). Composition of the bacterial community in the gut of the pine engraver, Ips pini (Say) (Coloptera) colonizing red pine. Symbiosos 43, 97-104.

Engel, P., Martinson, V. G., and Moran, N. A. (2012). Functional diversity within the simple gut microbiota of the honey bee. Proc. Natl. Acad. Sci. U.S.A. 109, 11002-11007. doi: 10.1073/pnas.1202970109 
Engel, P., and Moran, N. A. (2013). The gut microbiota of insects - diversity in structure and function. FEMS Microbiol. Rev. 37, 699-735. doi: 10.1111/15746976.12025

Firth, D. (1993). Bias reduction of maximum likelihood estimates. Biometrika 80 , 27-38. doi: 10.2307/2336755

Fisher, R. M., Henry, L. M., Cornwallis, C. K., Kiers, E. T., and West, S. A. (2017). The evolution of host-symbiont dependence. Nat. Commun. 8:15973. doi: $10.1038 /$ ncomms 15973

Freitak, D., Wheat, C. W., Heckel, D. G., and Vogel, H. (2007). Immune system responses and fitness costs associated with consumption of bacteria in larvae of Trichoplusia ni. BMC Biol. 5:56. doi: 10.1186/1741-7007-5-56

Frost, C. L., Fernández-Marín, H., Smith, J. E., and Hughes, W. O. H. (2010). Multiple gains and losses of Wolbachia symbionts across a tribe of fungus-growing ants. Mol. Ecol. 19, 4077-4085. doi: 10.1111/j.1365-294X.2010. 04764.x

Funaro, C. F., Kronauer, D. J. C., Moreau, C. S., Goldman-Huertas, B., Pierce, N. E., and Russell, J. A. (2011). Army ants harbor a host-specific clade of Entomoplasmatales bacteria. Appl. Environ. Microbiol. 77, 346-350. doi: 10.1128/AEM.01896-10

Gilbert, L. I., Lawrence, I., Iatrou, K., and Gill, S. S. (2005). Comprehensive Molecular Insect Science. Oxford: Elsevier.

Gilliam, M. (1971). Microbial sterility of the intestinal content of the immature honey bee, Apis mellifera. Ann. Entomol. Soc. Am. 64, 315-316. doi: 10.1093/ aesa/64.1.315

Gilliam, M., and Prest, D. B. (1987). Microbiology of feces of the larval honey bee, Apis mellifera. J. Invertebr. Pathol. 49, 70-75. doi: 10.1016/0022-2011(87) 90127-3

Hammer, T. J., McMillan, W. O., and Fierer, N. (2014). Metamorphosis of a butterfly-associated bacterial community. PLOS ONE 9:e86995. doi: 10.1371/ journal.pone.0086995

Hammer, Ø., Harper, D. A. T., and Ryan, P. D. (2001). Paleontological statistics software package for education and data analysis. Palaeontol. Electron. 4, 9-18.

Ishak, H. D., Plowes, R., Sen, R., Kellner, K., Meyer, E., Estrada, D. A., et al. (2011). Bacterial diversity in Solenopsis invicta and Solenopsis geminata ant colonies characterized by $16 \mathrm{~S}$ amplicon 454 pyrosequencing. Microb. Ecol. 61, 821-831. doi: 10.1007/s00248-010-9793-4

Johnston, P. R., and Rolff, J. (2015). Host and symbiont jointly control gut microbiota during complete metamorphosis. PLOS Pathog. 11:e1005246. doi: 10.1371/journal.ppat.1005246

Kaiwa, N., Hosokawa, T., Nikoh, N., Tanahashi, M., Moriyama, M., Meng, X.-Y., et al. (2014). Symbiont-supplemented maternal investment underpinning host's ecological adaptation. Curr. Biol. 24, 2465-2470. doi: 10.1016/j.cub.2014.08.065

Kautz, S., Rubin, B. E. R., and Moreau, C. S. (2013). Bacterial infections across the ants: frequency and prevalence of Wolbachia, Spiroplasma, and Asaia. Psyche A J. Entomol. 2013, 1-11. doi: 10.1155/2013/936341

Kooij, P. W., Poulsen, M., Schiøtt, M., and Boomsma, J. J. (2015). Somatic incompatibility and genetic structure of fungal crops in sympatric Atta colombica and Acromyrmex echinatior leaf-cutting ants. Fungal Ecol. 18, 10-17. doi: 10.1016/j.funeco.2015.08.003

Kozich, J. J., Westcott, S. L., Baxter, N. T., Highlander, S. K., and Schloss, P. D. (2013). Development of a dual-index sequencing strategy and curation pipeline for analyzing amplicon sequence data on the miseq illumina sequencing platform. Appl. Environ. Microbiol. 79, 5112-5120. doi: 10.1128/AEM.01043-13

Kwong, W. K., and Moran, N. A. (2016). Gut microbial communities of social bees. Nat. Rev. Microbiol. 14, 374-384. doi: 10.1038/nrmicro.2016.43

Lee, A. H., and Hooper-Bui, L. (2012). The origin and in situ identification of uncultured gut bacteria in fourth-instar larvae of the red imported fire ant, Solenopsis invicta (Hymenoptera: Formicidae). Sociobiology 59, 27-48. doi: 10. 13102/sociobiology.v59i1.665

Lee, A. H., Husseneder, C., and Hooper-Bùi, L. (2008). Culture-independent identification of gut bacteria in fourth-instar red imported fire ant, Solenopsis invicta Buren, larvae. J. Invertebr. Pathol. 98, 20-33. doi: 10.1016/j.jip.2007.10. 008

Liberti, J., Sapountzis, P., Hansen, L. H., Sørensen, S. J., Adams, R. M. M., and Boomsma, J. J. (2015). Bacterial symbiont sharing in Megalomyrmex social parasites and their fungus-growing ant hosts. Mol. Ecol. 24, 3151-3169. doi: $10.1111 / \mathrm{mec} .13216$
López-Madrigal, S., Balmand, S., Latorre, A., Heddi, A., Moya, A., Gil, R., et al. (2013). How does Tremblaya princeps get essential proteins from its nested partner Moranella endobia in the mealybug Planoccocus citri? PLOS ONE 8:e77307. doi: 10.1371/journal.pone.0077307

Martins, C., Souza, R. F., and Bueno, O. C. (2012). Presence and distribution of the endosymbiont Wolbachia among Solenopsis spp. (Hymenoptera: Formicidae) from Brazil and its evolutionary history. J. Invertebr. Pathol. 109, 287-296. doi: 10.1016/j.jip.2012.01.001

Martinson, V. G., Danforth, B. N., Minckley, R. L., Rueppell, O., Tingek, S., and Moran, N. A. (2011). A simple and distinctive microbiota associated with honey bees and bumble bees. Mol. Ecol. 20, 619-628. doi: 10.1111/j.1365-294X.2010. 04959.x

Martinson, V. G., Moy, J., and Moran, N. A. (2012). Establishment of characteristic gut bacteria during development of the honeybee worker. Appl. Environ. Microbiol. 78, 2830-2840. doi: 10.1128/AEM.07810-11

Meirelles, L. A., Mcfrederick, Q. S., Rodrigues, A., Mantovani, J. D., de Melo Rodovalho, C., Ferreira, H., et al. (2016). Bacterial microbiomes from vertically transmitted fungal inocula of the leaf-cutting ant Atta texana. Environ. Microbiol. Rep. doi: 10.1111/1758-2229.12415 [Epub ahead of print].

Mikonranta, L., Mappes, J., Kaukoniitty, M., and Freitak, D. (2014). Insect immunity: oral exposure to a bacterial pathogen elicits free radical response and protects from a recurring infection. Front. Zool. 11:23. doi: 10.1186/1742-999411-23

Mohr, K. I., and Tebbe, C. C. (2006). Diversity and phylotype consistency of bacteria in the guts of three bee species (Apoidea) at an oilseed rape field. Environ. Microbiol. 8, 258-272. doi: 10.1111/j.1462-2920.2005.00893.x

Moran, N. A., McCutcheon, J. P., and Nakabachi, A. (2008). Genomics and evolution of heritable bacterial symbionts. Annu. Rev. Genet. 42, 165-190. doi: 10.1146/annurev.genet.41.110306.130119

Nygaard, S., Hu, H., Li, C., Schiøtt, M., Chen, Z., Yang, Z., et al. (2016). Reciprocal genomic evolution in the ant-fungus agricultural symbiosis. Nat. Commun. 7:12233. doi: $10.1038 /$ ncomms 12233

Parthasarathy, R., and Palli, S. R. (2008). Proliferation and differentiation of intestinal stem cells during metamorphosis of the red flour beetle, Tribolium castaneum. Dev. Dyn. 237, 893-908. doi: 10.1002/dvdy.21475

Pietri, J. E., DeBruhl, H., and Sullivan, W. (2016). The rich somatic life of Wolbachia. Microbiologyopen 5, 923-936. doi: 10.1002/ mbo3.390

Quinlan, R. J., and Cherrett, J. M. (1979). The role of fungus in the diet of the leafcutting ant Atta cephalotes (L.). Ecol. Entomol. 4, 151-160. doi: 10.1111/j.13652311.1979.tb00570.x

R Core Team (2016). A Language and Environment for Statistical Computing. Vienna: R Foundation for Statistical Computing.

Rosengaus, R. B., Malak, T., and MacKintosh, C. (2013). Immune-priming in ant larvae: social immunity does not undermine individual immunity. Biol. Lett. 9:20130563. doi: 10.1098/rsbl.2013.0563

Salem, H., Florez, L., Gerardo, N., and Kaltenpoth, M. (2015). An out-of-body experience: the extracellular dimension for the transmission of mutualistic bacteria in insects. Proc. R. Soc. B Biol. Sci. 282:20142957. doi: 10.1098/rspb. 2014.2957

Sapountzis, P., Zhukova, M., Hansen, L. H., Sørensen, S. J., Schiøtt, M., and Boomsma, J. J. (2015). Acromyrmex leaf-cutting ants have simple gut microbiota with nitrogen-fixing potential. Appl. Environ. Microbiol. 81, 5527-5537. doi: 10.1128/AEM.00961-15

Sauer, C., Dudaczek, D., Hölldobler, B., and Gross, R. (2002). Tissue localization of the endosymbiotic bacterium "Candidatus Blochmannia floridanus" in adults and larvae of the carpenter ant Camponotus floridanus. Appl. Environ. Microbiol. 68, 4187-4193.

Schloss, P. D., Westcott, S. L., Ryabin, T., Hall, J. R., Hartmann, M., Hollister, E. B., et al. (2009). Introducing mothur: open-source, platform-independent, community-supported software for describing and comparing microbial communities. Appl. Environ. Microbiol. 75, 7537-7541. doi: 10.1128/AEM. 01541-09

Schmid-Hempel, P. (1998). Parasites in Social Insects. Princeton, NJ: Princeton University Press.

Schneider, M. O., Bueno, O. C., Hebling, M. J. A., and Pagnocca, F. C. (2000). "Observations on brood care behavior of the leaf-cutting ant Atta sexdens L. 
(Hymenoptera, Formicidae)," in Proceedings of the XXI International Congress of Entomology, Foz do Iguaçu, 895.

Serbus, L. R., Casper-Lindley, C., Landmann, F., and Sullivan, W. (2008). The genetics and cell biology of Wolbachia-host interactions. Annu. Rev. Genet. 42, 683-707. doi: 10.1146/annurev.genet.41.110306.130354

Shoemaker, D., Ross, K. G., Keller, L., Vargo, E. L., and Werren, J. H. (2000). Wolbachia infections in native and introduced populations of fire ants (Solenopsis spp.). Insect Mol. Biol. 9, 661-673.

Stoll, S., Feldhaar, H., Fraunholz, M. J., and Gross, R. (2010). Bacteriocyte dynamics during development of a holometabolous insect, the carpenter ant Camponotus floridanus. BMC Microbiol. 10:308. doi: 10.1186/1471-2180-10-308

Suen, G., Scott, J. J., Aylward, F. O., Adams, S. M., Tringe, S. G., PintoTomás, A. A., et al. (2010). An insect herbivore microbiome with high plant biomass-degrading capacity. PLOS Genet. 6:e1001129. doi: 10.1371/journal. pgen. 1001129

Sze, M. A., Abbasi, M., Hogg, J. C., and Sin, D. D. (2014). A comparison between droplet digital and quantitative PCR in the analysis of bacterial $16 \mathrm{~S}$ load in lung tissue samples from control and COPD GOLD 2. PLOS ONE 9:e110351. doi: 10.1371/journal.pone.0110351

Tully, J. G., Rose, D. L., Hackett, K. J., Whitcomb, R. F., Carle, P., Bove, J. M., et al. (1989). Mycoplasma ellychniae sp. nov., a sterol-requiring Mollicute from the firefly beetle Ellychnia corrusca. Int. J. Syst. Bacteriol. 39, 284-289. doi: 10.1099/00207713-39-3-284

Vigneron, A., Masson, F., Vallier, A., Balmand, S., Rey, M., Vincent-Monégat, C., et al. (2014). Insects recycle endosymbionts when the benefit is over. Curr. Biol. 24, 2267-2273. doi: 10.1016/j.cub.2014.07.065

Viljakainen, L., Reuter, M., and Pamilo, P. (2008). Wolbachia transmission dynamics in Formica wood ants. BMC Evol. Biol. 8:55. doi: 10.1186/1471-21 48-8-55

Vojvodic, S., Rehan, S. M., and Anderson, K. E. (2013). Microbial gut diversity of Africanized and European honey bee larval instars. PLOS ONE 8:e72106. doi: 10.1371/journal.pone.0072106
Watanabe, K., Yukuhiro, F., Matsuura, Y., Fukatsu, T., and Noda, H. (2014). Intrasperm vertical symbiont transmission. Proc. Natl. Acad. Sci. U.S.A. 111, 7433-7437. doi: 10.1073/pnas.1402476111

Wenseleers, T., Ito, F., Van Borm, S., Huybrechts, R., Volckaert, F., and Billen, J. (1998). Widespread occurrence of the micro-organism Wolbachia in ants. Proc. Biol. Sci. 265, 1447-1452. doi: 10.1098/rspb.1998. 0456

Wong, C. N. A., Ng, P., and Douglas, A. E. (2011). Low-diversity bacterial community in the gut of the fruitfly Drosophila melanogaster. Environ. Microbiol. 13, 1889-1900. doi: 10.1111/j.1462-2920.2011. 02511.x

Wu, Y., Parthasarathy, R., Bai, H., and Palli, S. R. (2006). Mechanisms of midgut remodeling: juvenile hormone analog methoprene blocks midgut metamorphosis by modulating ecdysone action. Mech. Dev. 123, 530-547. doi: 10.1016/j.mod.2006.05.005

Yun, J.-H., Roh, S. W., Whon, T. W., Jung, M.-J., Kim, M.-S., Park, D.-S., et al. (2014). Insect gut bacterial diversity determined by environmental habitat, diet, developmental stage, and phylogeny of host. Appl. Environ. Microbiol. 80, 5254-5264. doi: 10.1128/AEM. 01226-14

Conflict of Interest Statement: The authors declare that the research was conducted in the absence of any commercial or financial relationships that could be construed as a potential conflict of interest.

Copyright (®) 2017 Zhukova, Sapountzis, Schiøtt and Boomsma. This is an openaccess article distributed under the terms of the Creative Commons Attribution License (CC BY). The use, distribution or reproduction in other forums is permitted, provided the original author(s) or licensor are credited and that the original publication in this journal is cited, in accordance with accepted academic practice. No use, distribution or reproduction is permitted which does not comply with these terms. 